\title{
Modeling the Effect of Plants and Peat on Evapotranspiration in Constructed Wetlands
}

\author{
Florent Chazarenc, ${ }^{1,2}$ Simon Naylor, ${ }^{2}$ Yves Comeau, ${ }^{2}$ Gérard Merlin, ${ }^{3}$ and Jacques Brisson ${ }^{1}$ \\ ${ }^{1}$ Institut de Recherche en Biologie végétale, Université de Montréal, 4101 Sherbrooke St. East, Montréal, QC, Canada H1X $2 B 2$ \\ ${ }^{2}$ Department of Civil, Geological and Mining Engineering, École Polytechnique, Montréal, QC, Canada H3C $3 A 7$ \\ ${ }^{3}$ Laboratoire Optimisation de la Conception et Ingénierie de l'Environnement, Université de Savoie, Campus Scientifique, \\ 73376 Le Bourget du Lac Cedex, France
}

Correspondence should be addressed to Florent Chazarenc, florent.chazarenc@emn.fr

Received 15 January 2010; Accepted 17 April 2010

Academic Editor: Evans M. Nkhalambayausi-Chirwa

Copyright ( $\odot 2010$ Florent Chazarenc et al. This is an open access article distributed under the Creative Commons Attribution License, which permits unrestricted use, distribution, and reproduction in any medium, provided the original work is properly cited.

\begin{abstract}
Evapotranspiration (ET) in constructed wetlands (CWs) represents a major factor affecting hydrodynamics and treatment performances. The presence of high ET was shown to improve global treatment performances, however ET is affected by a wide range of parameters including plant development and CWs age. Our study aimed at modelling the effect of plants and peat on ET in CWs; since we hypothesized peat could behave like the presence of accumulated organic matter in old CWs. Treatment performances, hydraulic behaviour, and ET rates were measured in eight $1 \mathrm{~m}^{2}$ CWs mesocosm (1 unplanted, 1 unplanted with peat, 2 planted with Phragmites australis, 2 planted with Typha latifolia and 2 planted with Phragmites australis with peat). Two models were built using first order kinetics to simulate COD and TKN removal with ET as an input. The effect of peat was positive on ET and was related to the better growth conditions it offered to macrophytes. Removal efficiency in pilot units with larger ET was higher for TKN. On average, results show for COD a k20 value of $0.88 \mathrm{~d}^{-1}$ and $0.36 \mathrm{~d}^{-1}$ for TKN. We hypothesized that the main effect of ET was to concentrate effluent, thus enhancing degradation rates.
\end{abstract}

\section{Introduction}

In constructed wetlands (CWs) for wastewater treatment, evapotranspiration (ET) may represent a major factor increasing the hydraulic residence time (HRT) during summer months in temperate countries. In horizontal subsurface flow constructed wetlands (HSSFCWs), ET ranges between 0 and $50 \mathrm{~mm} / \mathrm{d}$ [1] and can reach up to $200 \mathrm{~mm} / \mathrm{d}$ in favorable periods [2]. High ET may improve global treatment performances [3] and modify water flow [4]. ET follows a diurnal cycle and is affected by a wide range of parameters such as plant development, CW design (surface, subsurface or vertical flow), and CW age [5].

Simulations were used to predict the performance of CWs using a direct plug flow reactor model [1], a plug flow with axial dispersion model (PFD) [4, 6-8], a stirred tank in series model [9] or a combination of these models [10]. One of the most limiting factors in predicting CWs efficiency was identified as the hydraulic behavior governed by environmental conditions $[11,12]$. Furthermore, in modeling or design equations, ET can be taken into account as an input to the model [8].

The aim of our work was first to determine (1) the effect of peat and of plant species on ET, since we hypothesized peat could behave like presence of accumulated organic matter in old CWs and (2) the importance of ET on treatment performances in an experimental constructed wetland system. The hydraulic behavior of pilot scale CWs was modeled during high ET rate periods and with ET values as an input of the hydraulics and performance models.

\section{Material and Methods}

Eight $1 \mathrm{~m}^{2}$ wetland mesocosms $(1.2 \mathrm{~m}$ long $\times 0.8 \mathrm{~m}$ wide $\times 0.3 \mathrm{~m}$ deep) were used in this study. Each mesocosm (Figure 1) was fed with $30 \mathrm{~L} / \mathrm{d}$ (two batches per day) of a reconstituted fish farm effluent $(187 \mathrm{mg}$ TSS/L, $373 \mathrm{mg}$ 


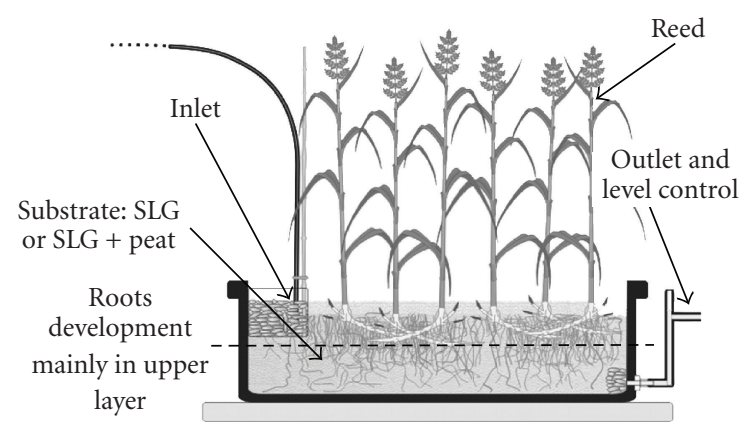

FIgURE 1: Section view of a mesocosm.

TABLE 1: Description of mesocosms, pulse input tracer, evapotranspiration, and aboveground biomass.

\begin{tabular}{lccccccc}
\hline $\begin{array}{l}\text { Pilot } \\
\text { ID }^{1}\end{array}$ & Plant & Peat & $\begin{array}{c}\text { Tracer } \\
\text { recovered }\end{array}$ & $\tau^{2}$ & $\mathrm{ts}^{3}$ & $\begin{array}{c}\text { Average } \\
\text { ET rates }\end{array}$ & $\begin{array}{c}\text { Above } \\
\text { ground } \\
\text { biomass } \\
\text { kg/m }\end{array}$ \\
\hline U1 & no & no & 75.5 & 3.6 & 5.4 & 0.3 & - \\
U2 & no & yes & 85.1 & 4.1 & 9.9 & 0.2 & - \\
R1 & Reed & no & 65.1 & 4.4 & 7.0 & 8.0 & 1.2 \\
R2 & Reed & no & 61.2 & 4.2 & 5.9 & 6.3 & 0.9 \\
C1 & Cattail & no & 67.4 & 3.9 & 5.9 & 3.8 & 0.2 \\
C2 & Cattail & no & 61.8 & 4.3 & 6.1 & 7.3 & 0.6 \\
R3 & Reed & yes & 27.2 & 6.0 & 7.7 & 16.7 & 2.3 \\
R4 & Reed & yes & 41.0 & 5.9 & 9.2 & 16.4 & 2.2 \\
\hline
\end{tabular}

${ }^{1}$ Adapted from Naylor et al. [13].

${ }^{2}$ Theoretical HRT $(\tau)$ was calculated following the method described in Chazarenc et al. [8].

${ }^{3}$ Experimental HRT (ts) was determined using integration of response curves.

COD/L and $12.4 \mathrm{mg}$ TKN/L). All mesocosms were filled with a combination of rock media (Table 1) and in four of them $60 \mathrm{~L}$ of peat was added and mixed (initially to reduce alkalinity caused by steel slag). The substrate was composed by mass of 25\% 5-10 mm electric arc furnace EAF-steel slag, 20\% 2.5-10 mm limestone, and 55\% of 2.5$10 \mathrm{~mm}$ granite gravel. Four mesocosms were planted with Phragmites australis, two with Typha latifolia and two were left unplanted (Table 1). Planting was done one year prior to the experiment, during the summer of 2000, to allow adequate establishment. More details on the experimental setup are provided by [13].

Experiments were conducted between July and August 2001 in a greenhouse at the Botanical Garden of Montreal. Concentration of TSS, COD, and TKN were measured daily at the inlet and outlet of each mesocosms according to standards methods [14]. Pulse input tracer studies were conducted using lithium chloride ( $\mathrm{LiCl}$ ) simultaneously in all eight mesocosms operating at the same inflow. HRT was estimated by injecting $15 \mathrm{~L}$ of tracer $(33 \mathrm{mg}$ $\mathrm{Li}^{+} / \mathrm{L}$ ) over a period of 5 minutes in each mesocosm and outlet concentrations were measured daily during 30 days. Lithium concentrations were determined by atomic absorption spectophotometry. The amount of daily water lost by ET was estimated as the difference between inflow and outflow. Treatment performances $(P)$ were calculated based on pollutant mass flow removal

$$
P=100 \cdot\left(1-\frac{Q i \cdot C i}{Q o \cdot C o}\right),
$$

where $Q=$ flow, $C=$ pollutant concentration, $i=$ inlet, $o=$ outlet.

2.1. Hydraulic Models. The plug flow with axial dispersion model (PFD) [15] was preferred to the classical plug flow model with a background concentration (see [16]). This choice was made in order to achieve the objective of estimating the effect of plant presence and activity on dispersion inside the mesocosm.

A second model was built (using the object oriented Visim software), based on the hypothesis of a two layers flows: (1) the surface layer modeling the rhizomial part of the mesocosm, with a time delay block taking into account ET, and (2) a bottom layer. The two-layer model (TLM) was built by associating several basic blocks (continuous stirred tank, plug flow and gain) specified using Laplace transforms (Figure 4).

2.2. Performance Models. COD and TKN treatment performances were predicted by using an integrated form of the two hydraulics models. Volumetric first order kinetics $(k)$ were assumed for COD and TKN degradation rate. The integrated forms of the PFD model [17] and of the TLM are presented respectively in

$$
\begin{aligned}
& \frac{C s}{C o}=\frac{4 \cdot a \cdot e^{(\mathrm{Pe} / 2)}}{(1+a)^{2} e^{(a \cdot \mathrm{Pe} / 2)}-(1-a)^{2} e^{(-a \cdot \mathrm{Pe} / 2)}} \\
& \text { with } a=\sqrt{1+\frac{4 \cdot k \cdot \tau}{\mathrm{Pe}}} \\
& \frac{C s}{C o}=G \cdot \frac{1}{(1+2 \cdot k)^{2}} \cdot e^{(-k \cdot \mathrm{td})}+(1-G) \cdot \frac{1}{(1+2 \cdot k)^{2}},
\end{aligned}
$$

with $C s, C o$ : outlet and inlet COD and TKN concentration, respectively, $[\mathrm{mg} / \mathrm{L}]$, Pe: Péclet number according to PFD model. $\mathrm{Pe}=1 / D$ with $D$ System dispersion number $[-], \tau$ : HRT estimated with PFD model [d]. td: time delay in first layer of the conceptualized model [d], $k$ : first-order volumetric kinetic constant $\left[\mathrm{d}^{-1}\right] . k=k_{20}(\theta)\left(T^{-20}\right)$ with $T$ effective temperature. $\theta$ constant (1.06). $k_{20}$ first-order volumetric kinetic constant at $20^{\circ} \mathrm{C}$, determined for COD and TKN $\left[\mathrm{d}^{-1}\right] . G$ : ratio in the first layer of the TLM model $[-]$

Those two models have been used to simulate treatment performances on COD and TKN removal during the 30 days of test.

\section{Results And Discussion}

3.1. Influence of Peat on ET Rates and Hydraulic. On average, ET was highest in planted peat mesocosms $(16.7 \mathrm{~mm} / \mathrm{d}$ 
TABLE 2: Simulation results of hydraulic models ( ${ }^{*}$ Pearson correlation).

\begin{tabular}{ccccccc}
\hline & \multicolumn{3}{c}{ PFD model } & \multicolumn{3}{c}{ TLM Visim model } \\
\hline & $\mathrm{D}$ & $\tau_{\text {PFD }}$ & \multicolumn{5}{c}{ Ratio in layer } \\
& $(-)$ & $($ day $)$ & $R^{2 \star}$ & $1(\mathrm{G})$ & Time delay & $R^{2 \star}$ \\
\hline $\mathrm{U} 1$ & 0.21 & 3 & 99.6 & 0.5 & 0 & 98.1 \\
$\mathrm{U} 2$ & 0.36 & 3.6 & 97.8 & - & - & - \\
$\mathrm{R} 1$ & 0.14 & 4.4 & 97.1 & 0.7 & 1.7 & 95.1 \\
$\mathrm{R} 2$ & 0.25 & 3.4 & 98.7 & 0.6 & 0.8 & 97 \\
$\mathrm{C} 1$ & 0.3 & 3 & 97.8 & 0.6 & 0.4 & 94.8 \\
$\mathrm{C} 2$ & 0.27 & 3.2 & 95.4 & 0.6 & 0.4 & 95.3 \\
\hline
\end{tabular}

in R3) and lowest in the unplanted control without peat $(0.1 \mathrm{~mm} / \mathrm{d}$ in U1). Maximal daily values were estimated at $20 \mathrm{~mm} / \mathrm{d}$ in R3 and R4, which are in accordance with values proposed in the literature $[1,3,4]$.

Association between reed and peat generated the most important ET rates (Table 2). The positive effect of peat on ET can be explained on the one hand by the better growth conditions it offered to plants (presence of more plant biomass). On the other, the effect of peat on mesocosms hydraulic behavior was hypothesized to be similar to accumulated organic matter appearing in constructed wetlands over time [18]. As observed between the two unplanted units, peat enhanced the retention by acting as a sponge. In absence of peat, while the HRT remained fairly close to the theoretical value in $\mathrm{U} 1$, it was up to $30 \%$ greater than the theoretical hydraulic residence time value in pilot units with high ET (those with large active macrophytes). Experimental HRT, determined using response curves (Figure 2), were always greater than theoretical values (Table 2). This was a possible consequence of the non-ideal flow in the different reactors.

\subsection{Influence of Plant Presence and Species on ET Rates and} Hydraulic. Effects of Phragmites and Typha on ET rates were similar (Table 2). The relationship between ET and plants seemed mostly related to plant biomass irrespective of plant species.

The ratio of tracer collected at outlets was sufficient for a more detailed analysis in all cases except for the R3 and R4 mesocosms where less than $45 \%$ of the tracer was recovered (Table 1). In the response curves of the R3 and R4 mesocosms, a small tracer peak was observed after which lithium concentrations never returned to background levels, even after 30 days (not shown). This was most probably the consequence of the sorption of lithium by peat (also observed in a minor extend in unplanted U2) followed by slow release back into solution [19] associated to ET cumulative effects. Results from R3 and R4 were not further analyzed.

The PFD and the TLM models (Figure 4) were used to fit the experimental response curve. System dispersion numbers $(D)$, estimated by fitting experimental data with PFD model, were in the range of 0.14 to 0.36 (Figure 3 ) which is in the observed range of 0.009 to 0.48 for $D$ values in HSSFCWs [1]. In HSSFCWs it was shown that presence of high rates of ET generally leads to a decrease of $D$ values $[4,8]$. In our study,

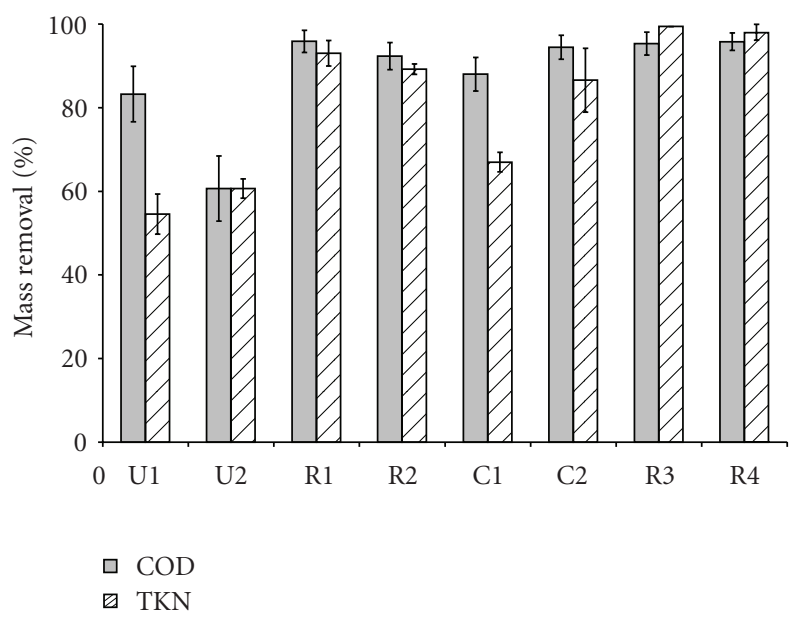

FIgURE 2: Treatment performances during the 30-day test.

there was little variation in $D$ values between mesocosms. This was probably due to the small size of the mesocosms which led to a permanent bypass along the wall.

3.3. Effect of ET Rates on COD and TKN Removal, Modeling. No TSS removal differences were found between the different mesocosms (results not shown). COD removal was higher in $\mathrm{U} 1$ than in $\mathrm{U} 2$, and this was likely due to the release of organic carbon by the peat. This difference was less pronounced between R1 and R2 (planted with reed) and R3 and R4 (planted with reed and with peat). Overall, there were slight differences between performances of all the planted mesocosms for COD degradation (Figure 1), irrespective of ET and plant species.

Removal efficiency in pilot units with higher ET (more than $50 \%$ of inflow) was greater for TKN (Figure 1). In R3 and $\mathrm{R} 4$ mesocosms, average net rate of $\mathrm{N}$ mineralization values of $0.36 \mathrm{~g} \mathrm{~m}^{-2} \mathrm{~d}^{-1}$ were reported (which represented almost all of the input) until in unplanted units it was about $0.15 \mathrm{~g} \mathrm{~m}^{-2} \mathrm{~d}^{-1}$. In similar pilot units and experimental conditions, rates of 0.22 to $0.53 \mathrm{~g} \mathrm{~m}^{-2} \mathrm{~d}^{-1}$ have been reported [20]. Nitrification should have been enhanced by the presence of well established plant biomass associated to high ET rates, furthermore the contact time between plants shoots (the principal oxygen supplier in HSSFCWs) and effluent was extended.

Performance models (2) were used to predict treatment performances of pilots U1, R1, R2, C1, C2. The first step was to determine the best $k_{20}$ value for COD and TKN, to fit the model with experimental data. On average, results show a $k_{20}$ value of 0.88 for COD removal and 0.36 for TKN removal. Large ranges of annual average values, from 0.06 to 6.11 for $\mathrm{BOD}_{5}$ and from 0.06 to 0.16 for TKN are reported for CWs [16]. Our results are on the same order for COD (while assuming a ratio of 0.25 for $\mathrm{BOD}_{5} / \mathrm{COD}$ ). High values obtained for TKN kinetics are probably a consequence of the favourable conditions (high temperatures, plant activities) during the experiment. 


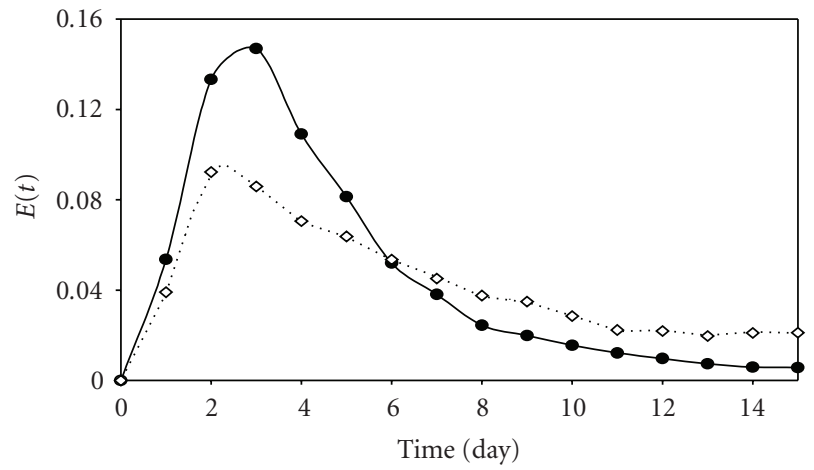

- U1: Unplanted 1

•.. U2: Unplanted 2 (peat)

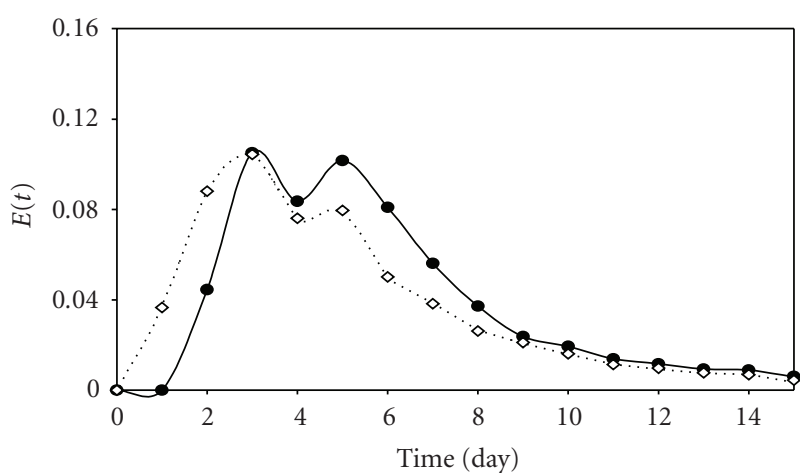

$\longrightarrow$ R1: Reed 1

$\cdots \diamond$ R2: Reed 2

(a)

(b)

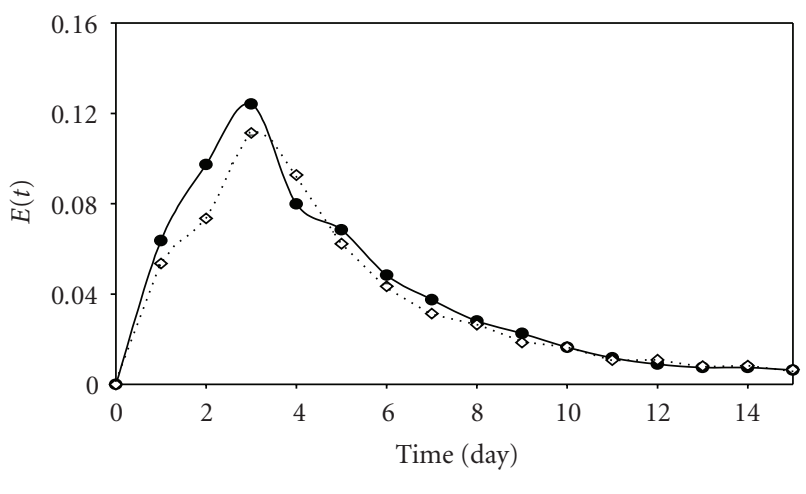

$\rightarrow$ C1: Cattail 1

๑.. C2: Cattail 2

(c)

FIGURE 3: Response curves of the different pilots.

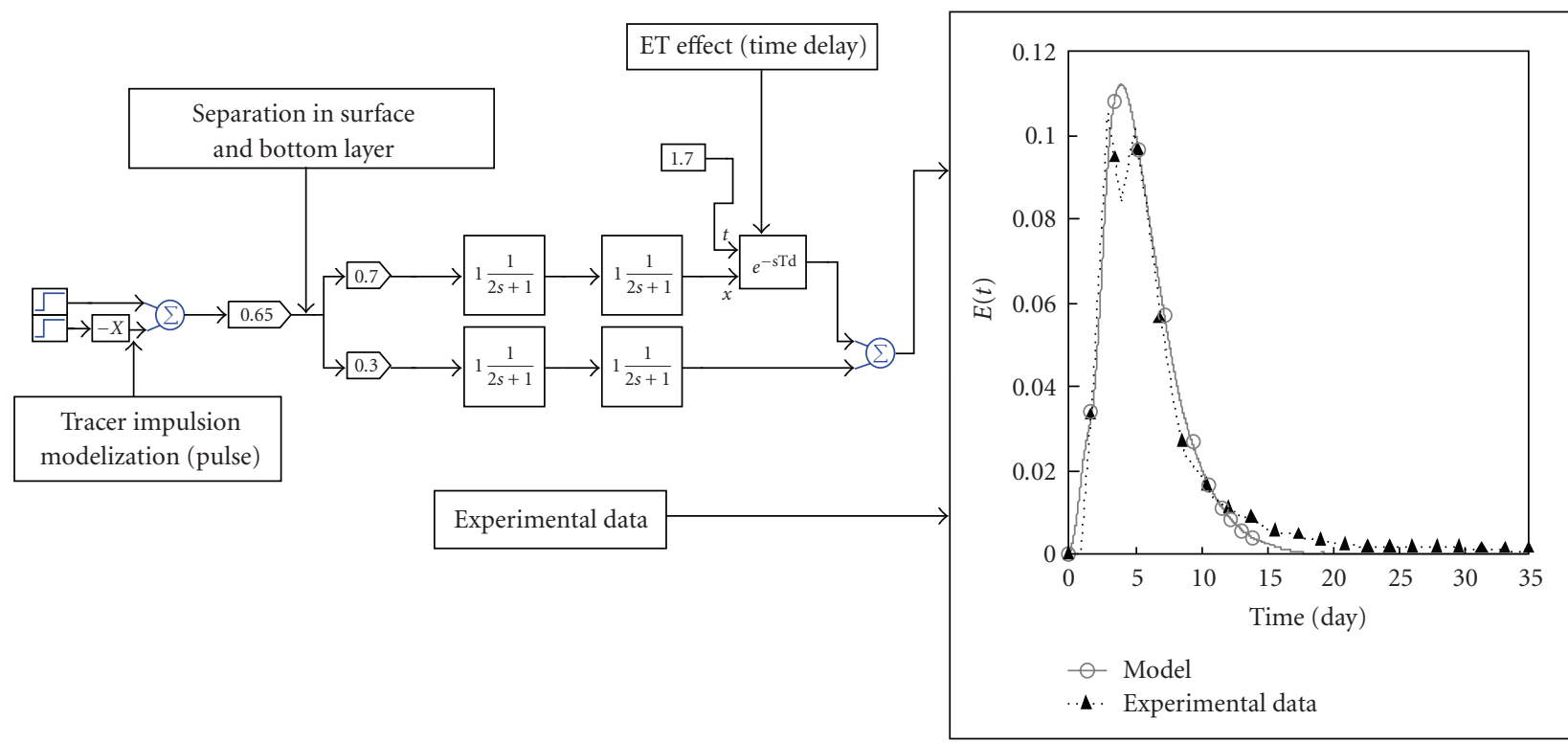

FIgure 4: Conceptualized two-layer model (TLM) with results from R1. 


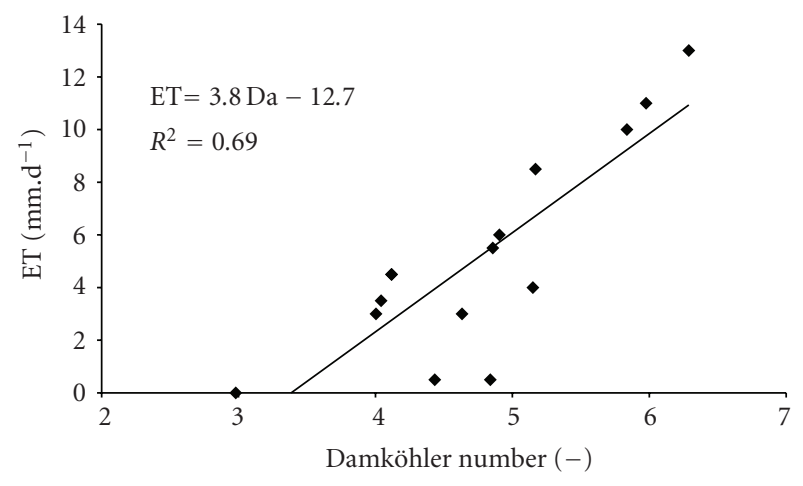

FIGURE 5: Relationship between Damköhler number and ET for TKN degradation (except for R3 and R4).

Simulation results were closer to experimental data when using the TLM, but care should be taken when interpreting the correlation coefficients obtained. Simulation with PDF model $\left(R^{2}=0.46\right.$ for COD and 0.33 for TKN) seemed to give inferior results than simulation with TLM model $\left(R^{2}=\right.$ 0.94 for COD and 0.71 for TKN). The only input in the PFD model was the Peclet number while the TLM model counted two inputs, the $G$ ratio and the total delay (Td), which led to a more accurate determination of performances. On the other hand, the TLM enabled a better comprehension of flow and removal gradient in mesocosms. The ratio " $G$ " used in the TLM model was proportional to ET magnitude and the time delay increased with high ET (Table 2).

The Damköhler number $(\mathrm{Da}=k \cdot \tau)$ is the normalised first order reaction rate constant and is defined as the ratio of the degradation rate to the mass transfer rate. A correlation between ET and Da values for TKN removal was underlined for all cases except pilots R3 and R4 (Figure 5). This suggested that ET enhanced the degradation rates. We hypothesised that the first effect of ET was to concentrate effluent, thus enhancing degradation rates (especially for TKN). Another contribution of ET could have been the amplification of gas transfer in aerenchyma, thus enhancing oxygen supply in the rhizosphere.

\section{Conclusion}

A positive contribution of peat on plant biomass development and consequently ET rates was observed. Effects of peat can also be related to those of large amounts of accumulated organic matter that can be found in old constructed wetlands. Thus adding peat in young CWs represents a clear improvement for plant establishment and can increase treatment performances for TKN.

In our study, the effects of ET were not clearly observed in hydraulic behavior by modeling the different mesocosms. No effect of ET on the dispersion coefficient was observed when using the plug flow with axial dispersion model. This was probably due to the small size of the mesocosms which led to a permanent bypass along the wall.

There was no clear difference between Phragmites and Typha effect on ET rates. The major factor increasing the
ET was most likely the amount of plant biomass. Effect of ET was beneficial to TKN removal by increasing HRT. In temperate countries, favoring ET (building CWs well exposed to sun light) represents a clear increase on treatment performances, especially TKN. Effects of peat and of large ET on hydrodynamics of full scale CWs have to be measured to confirm those results.

\section{Acknowledgments}

The authors would like to thank Marc-André Labelle and Vincent Gagnon for technical assistance and Dwight Houweling for reviewing an earlier draft of the paper. This research was financed by the Natural Sciences and Engineering Research Council of Canada (NSERC).

\section{References}

[1] R. H. Kadlec and R. L. Knight, Treatment Wetlands, Lewis Publishers, New York, NY, USA, 1996.

[2] A. Thompson, D. R. Parker, and C. Amrhein, "Selenate partitioning in field-situated constructed wetland mesocosms," Ecological Engineering, vol. 20, no. 1, pp. 17-30, 2003.

[3] Q. He and K. R. Mankin, "Seasonal variations in hydraulic performance of rock-plant filters," Environmental Technology, vol. 22, no. 9, pp. 991-999, 2001.

[4] M. E. Grismer, M. Tausendschoen, and H. L. Shepherd, "Hydraulic characteristics of a subsurface flow constructed wetland for winery effluent treatment," Water Environment Research, vol. 73, no. 4, pp. 466-477, 2001.

[5] International Water Association (IWA), "Constructed wetland for pollution control: processes, performance, design and operation," Scientific and Technical Report 8, IWA Publishing, London, UK, 2000.

[6] A. C. King, C. A. Mitchell, and T. Howes, "Hydraulic tracer studies in a pilot scale subsurface flow constructed wetland," Water Science and Technology, vol. 35, no. 5, pp. 189-196, 1997.

[7] T. Machate, H. Noll, H. Behrens, and A. Kettrup, "Degradation of phenanthrene and hydraulic characteristics in a constructed wetland," Water Research, vol. 31, no. 3, pp. 554-560, 1997.

[8] F. Chazarenc, G. Merlin, and Y. Gonthier, "Hydrodynamics of horizontal subsurface flow constructed wetlands," Ecological Engineering, vol. 21, no. 2-3, pp. 165-173, 2003.

[9] E. T. Volger, J. S. Scherfig, S. Chen, and G. T. Wang, "Modeling BOD removal in constructed wetlands with mixing cell method," Journal of Environmental Engineering, vol. 126, no. 8, pp. 782-785, 2000.

[10] T. M. Werner and R. H. Kadlec, "Application of residence time distributions to stormwater treatment systems," Ecological Engineering, vol. 7, no. 3, pp. 213-234, 1996.

[11] R. H. Kadlec, "The inadequacy of first-order treatment wetland models," Ecological Engineering, vol. 15, no. 1-2, pp. 105-119, 2000.

[12] T. M. Wynn and S. K. Liehr, "Development of a constructed subsurface-flow wetland simulation model," Ecological Engineering, vol. 16, no. 4, pp. 519-536, 2001.

[13] S. Naylor, J. Brisson, M. A. Labelle, A. Drizo, and Y. Comeau, "Treatment of freshwater fish farm effluent using constructed wetlands: the role of plants and substrate," Water Science and Technology, vol. 48, no. 5, pp. 215-222, 2003. 
[14] APHA, AWWA, WEF, Standard Methods for the Examination of Water and Wastewater, APHA \& WEF, Washington, DC, USA, 21th edition, 2005.

[15] O. Levenspiel, Chemical Reaction Engineering, John Wiley \& Sons, New York, NY, USA, 1972.

[16] D. P. L. Rousseau, P. A. Vanrolleghem, and N. De Pauw, "Model-based design of horizontal subsurface flow constructed treatment wetlands: a review," Water Research, vol. 38, no. 6, pp. 1484-1493, 2004.

[17] S. Fogler, Elements of Chemical Reaction Engineering, PrenticeHall, New York, NY, USA, 2nd edition, 1992.

[18] C. C. Tanner, J. P. S. Sukias, and M. P. Upsdell, "Organic matter accumulation during maturation of gravel-bed constructed wetlands treating farm dairy wastewaters," Water Research, vol. 32, no. 10, pp. 3046-3054, 1998.

[19] T. R. Headley, M. L. Bayley, and L. Davidson, "A comparison of Lithium, Bromide and Rhodamine B as tracers in gravel bed based reed beds," in Proceedings of the 8th International Conference on Constructed Wetland for Wastewater Pollution Control, pp. 266-274, Arusha, Tanzania, September 2002.

[20] C. C. Tanner, R. H. Kadlec, M. M. Gibbs, J. P. S. Sukias, and M. L. Nguyen, "Nitrogen processing gradients in subsurface-flow treatment wetlands-influence of wastewater characteristics," Ecological Engineering, vol. 18, no. 4, pp. 499-520, 2002. 

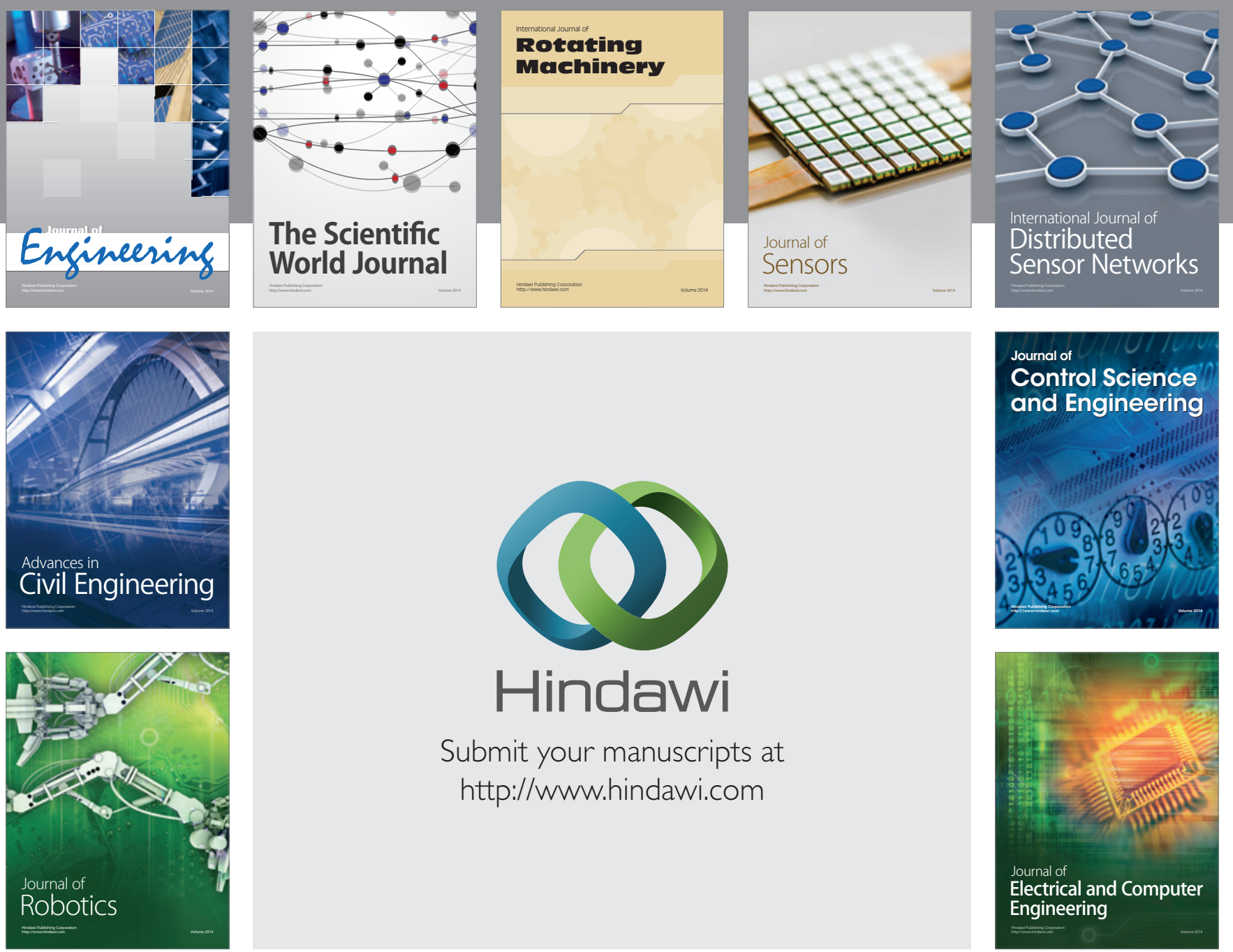

Submit your manuscripts at

http://www.hindawi.com
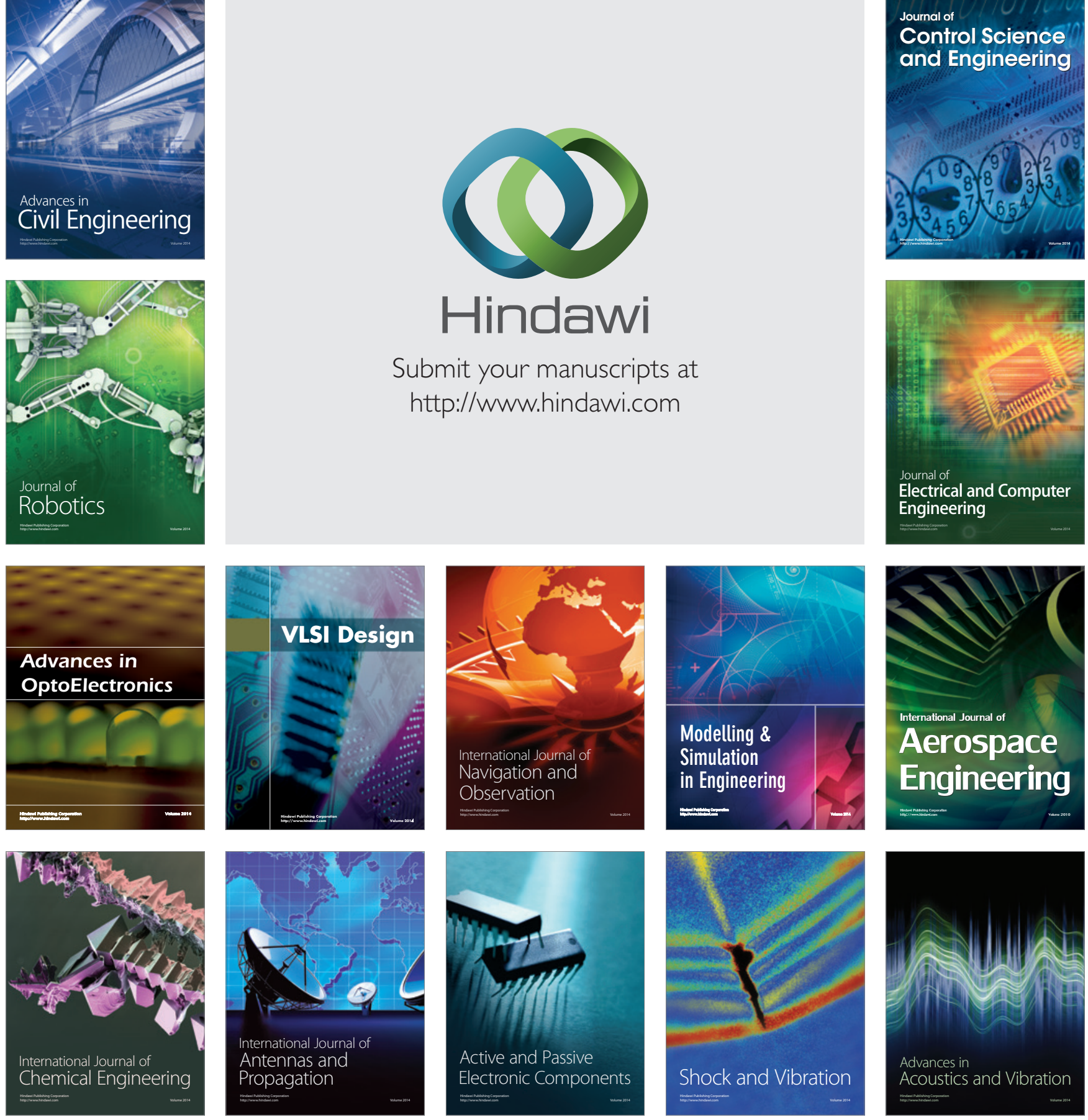